\title{
Copper-manganese-zinc spinels in zeolites: study of EMR spectra
}

Piotr Decyk, Andrzej B. Więckowski, Lidia Najder-Kozdrowska, Iveta Bilkova

\begin{abstract}
The aim of this study is the application of electron magnetic resonance (EMR) spectroscopy to determine the interactions between $\mathrm{NaY}$ and $\mathrm{HY}$ zeolites and $\mathrm{Cu}-\mathrm{Mn}-\mathrm{Zn}$ spinels loaded onto the zeolite surfaces. The materials were characterized using XRD and IR spectroscopies. Four types of EMR lines were observed for $\mathrm{Cu}-\mathrm{Mn}-\mathrm{Zn} / \mathrm{NaY}, \mathrm{Cu}-\mathrm{Mn}-\mathrm{Zn} / \mathrm{HY}$ samples. The difference between the EMR spectra recorded at 77 and $293 \mathrm{~K}$ has been shown. The spectra recorded at $77 \mathrm{~K}$ allowed us to distinguish between the species formed on NaY and $\mathrm{HY}$ zeolites. The EMR spectrum of $\mathrm{Cu}-\mathrm{Mn}-\mathrm{Zn} / \mathrm{NaY}$ recorded at $77 \mathrm{~K}$ showed only one line attributed to antiferromagnetic spinels $\mathrm{Cu}_{1.4} \mathrm{Mn}_{1.6} \mathrm{O}_{4}$ and $\mathrm{ZnMn}_{2} \mathrm{O}_{4}$ or/and $\mathrm{Cu}_{0.5} \mathrm{Zn}_{0.5} \mathrm{Mn}_{2} \mathrm{O}_{4}$. The spinels appeared to be more stable (more strongly attached) on $\mathrm{HY}$ zeolite than on $\mathrm{NaY}$ one. It was proved that different strength of interactions between the zeolites and $\mathrm{Cu}-\mathrm{Mn}-\mathrm{Zn}$ spinels was caused by differences in the acidity of NaY and HY zeolites.
\end{abstract}

Key words: $\mathrm{Cu}-\mathrm{Mn}-\mathrm{Zn}$ spinels $\bullet$ electron magnetic resonance $\bullet$ paramagnetic complexes $\bullet$ Y zeolites

P. Decyk, I. Bilkova

Faculty of Chemistry,

Adam Mickiewicz University,

6 Grunwaldzka Str., 60-780 Poznań, Poland

\section{A. B. Więckowski ${ }^{凶}$}

Institute of Physics,

Faculty of Physics and Astronomy,

University of Zielona Góra,

4a Szafrana Str., 65-516 Zielona Góra, Poland and Institute of Molecular Physics of the Polish Academy of Sciences,

17 Smoluchowskiego Str., 60-179 Poznań, Poland,

Tel.: +48 504534 164,

E-mail: Andrzej.Wieckowski@vp.pl

L. Najder-Kozdrowska

Institute of Physics,

Faculty of Physics and Astronomy,

University of Zielona Góra,

4a Szafrana Str., 65-516 Zielona Góra, Poland

Received: 9 October 2014

Accepted: 30 January 2015

\section{Introduction}

Mixed oxides of copper and manganese have found many applications in laboratory and industry, e.g., in catalysis. Fierro et al. [1] performed the preparation and characterization of different catalysts containing $\mathrm{Cu}-\mathrm{Zn}-\mathrm{Mn}$ oxides. It has been also reported by Fei et al. $[2,3]$ that $\mathrm{Cu}-\mathrm{Mn}-\mathrm{Zn}$ oxides supported on $\mathrm{HY}$ zeolite are active catalysts for dimethyl ether (DME) synthesis from syngas via direct $\mathrm{CO}$ hydrogenation. One of components of these catalysts is the non-stoichiometric spinel $\mathrm{Cu}_{1.4} \mathrm{Mn}_{1.6} \mathrm{O}_{4}$ beside other $\mathrm{Cu}-\mathrm{Mn}-\mathrm{Zn}$ oxides. The system applied by Fei et al. [3] was chosen by us for the EMR study. Padlyak et al. [4] have employed EPR method to study $\mathrm{Mn}^{2+}$ and $\mathrm{Cu}^{2+}$ cations in lithium and potassium-lithium tetraborate glasses.

To the best of our knowledge, spinel compounds containing copper and manganese deposited on zeolites were not studied by the use of EMR spectroscopy. Bulk spinels of various compositions have been already investigated by $\operatorname{EMR~}[5,6]$, but no EMR studies of zeolite-supported $\mathrm{Cu}-\mathrm{Zn}$-Mn oxides have been reported so far. It is worth mentioning that the observation of changes in EMR spectra can provide information on interactions between components of the zeolite-Cu-Zn-Mn oxide system and this study is aimed at applying EMR spectroscopy to the characterization of such interactions. 


\section{Experimental}

In the present study, commercial $\mathrm{NaY}$ (Katalistiks) and $\mathrm{HY}$ zeolites have been used as supports for spinels. They were modified by copper-, manganese- and zinc-containing compounds according to the procedure given in Ref. [3]. The amount of $\mathrm{Cu}-\mathrm{Mn}-\mathrm{Zn}$ spinels on zeolites was 5 and $10 \mathrm{wt} \%$. The catalysts were characterized with the use of XRD and IR spectroscopic techniques. However, the main technique applied in this study was the EMR spectroscopy.

XRD patterns were recorded on an AXS D8 Advance, Bruker diffractometer using Ka radiation $(\lambda=0.154 \mathrm{~nm})$ in the step scanning mode of $0.05^{\circ}$ in the angle range between $10^{\circ}$ and $60^{\circ}$.

The XRD studies were complemented by Fourier-transform infrared (FTIR) spectroscopy. Infrared spectra were recorded on a Vector 22 (Bruker) spectrometer. The pellets were prepared using the sample and $\mathrm{KBr}(1 \mathrm{mg}$ and $200 \mathrm{mg}$, respectively) followed by pressing the mixture.

Surface properties of zeolites were studied by in situ FTIR spectroscopy of adsorbed pyridine. Self-supporting pellets of about $10 \mathrm{mg} / \mathrm{cm}^{2}$ were prepared and placed into a glass cell connected to a vacuum line. FTIR spectra were recorded at $293 \mathrm{~K}$. All the samples were activated at $673 \mathrm{~K}$ under vacuum before any characterization. Pyridine was adsorbed at $473 \mathrm{~K}$ and evacuated at various temperatures (473-673 K) for 30 min at each temperature. The FTIR spectra of the activated samples were subtracted from those recorded after pyridine adsorption.

The EMR measurements were carried out with an X-band EPR spectrometer type SE/X 2547 RADIOPAN. The operating microwave frequency was in the range of $8.9 \mathrm{GHz}$ with a magnetic field modulation of $100 \mathrm{kHz}$. For all samples under study, the spectra were recorded at room temperature $(293 \mathrm{~K})$ and at liquid nitrogen temperature ( $77 \mathrm{~K})$. Additionally, for all samples with the loading of $10 \mathrm{wt} \%$, EMR spectra were recorded in the temperature range of $77-373 \mathrm{~K}$.

\section{Results and discussion}

In order to distinguish which kind of zeolite surface centers participate in the interactions with spinels, pyridine adsorption on $\mathrm{NaY}$ and $\mathrm{HY}$ zeolites was performed. FTIR studies of adsorbed pyridine (Py) on $\mathrm{NaY}$ zeolite revealed the presence of very weak Lewis acidity coming from extralattice $\mathrm{Na}^{+}$cations $\left(\mathrm{Py}-\mathrm{Na}^{+}\right)$. This acidity is characterized by the presence of the band at $\sim 1445 \mathrm{~cm}^{-1}[7,8]$. Evacuation up to $523 \mathrm{~K}$ caused the disappearance of this band. On the other hand, no Brønsted acidity was detected on this zeolite, as evidenced by the absence of the band at $1549 \mathrm{~cm}^{-1}$, which can be ascribed to pyridine adsorbed on Brønsted acid sites (BAS) [8] (Fig. 1A).

In the case of HY zeolite, both Brønsted and Lewis acidities were observed. The strength of acid centers on the latter zeolite was much greater than
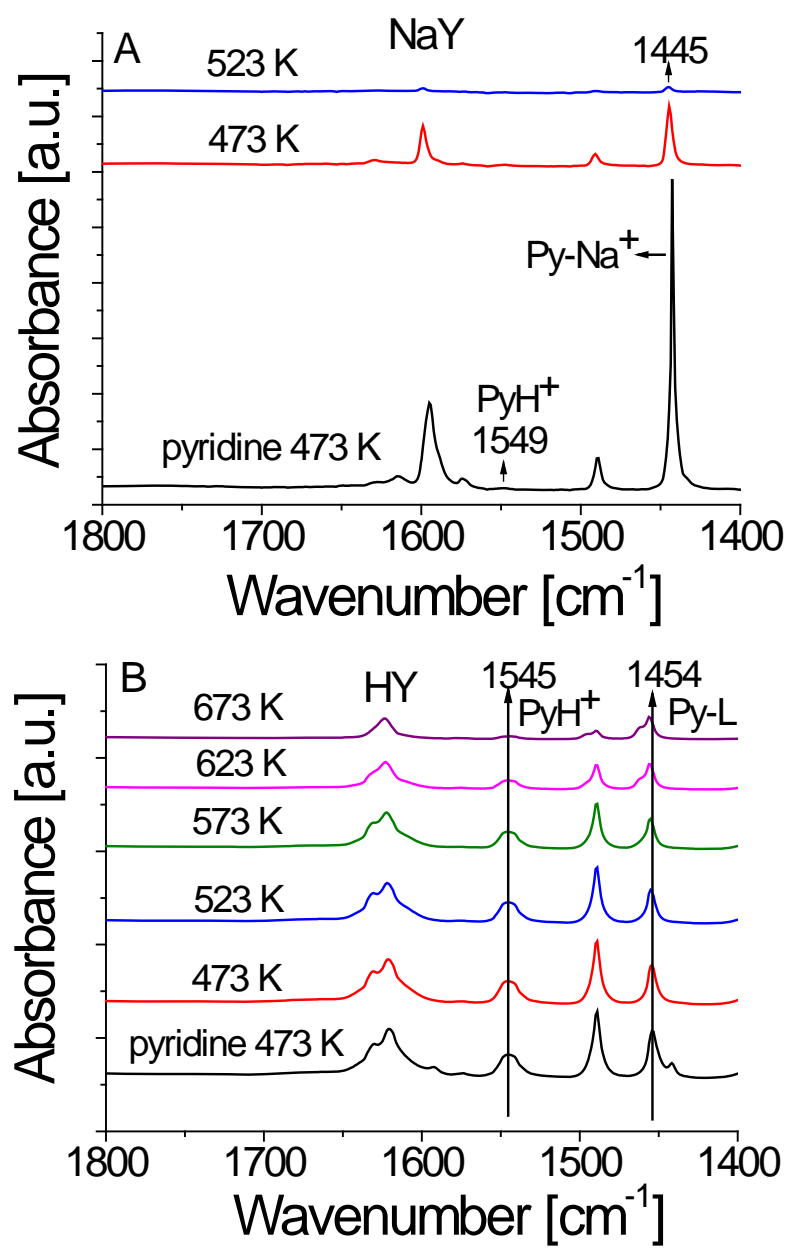

Fig. 1. FTIR spectra after pyridine adsorption and desorption in vacuum conditions at different temperatures on zeolites: A - NaY; B - HY.

that on $\mathrm{NaY}$ zeolite. The band at $1454 \mathrm{~cm}^{-1}$ originating from Lewis acidic sites (LAS) was clearly present even after evacuation at $673 \mathrm{~K}$. Brønsted acid sites that formed pyridinium cations $\left(\mathrm{PyH}^{+}\right)$after pyridine adsorption and gave the IR band at $\sim 1545 \mathrm{~cm}^{-1}$, as well as two other bands in the range of 1620-1640 $\mathrm{cm}^{-1}$ were also present (Fig. 1B).

XRD patterns and IR spectra recorded in the range of $400-1500 \mathrm{~cm}^{-1}$ confirmed that the crystal structure of the NaY and HY zeolites after deposition of the $\mathrm{Cu}-\mathrm{Mn}-\mathrm{Zn}$ spinels was preserved. XRD measurements have shown that beside the diffraction peaks from zeolites, additional two reflections appeared at $2 \theta=35.7^{\circ}$ and $36.4^{\circ}$ (Fig. 2). The XRD profiles of modified zeolites $\mathrm{Cu}-\mathrm{Mn}-\mathrm{Zn} / \mathrm{NaY}$ and $\mathrm{Cu}-\mathrm{Mn}-\mathrm{Zn} / \mathrm{HY}(10 \mathrm{wt} \%)$ as well as the spinels calcined at $723 \mathrm{~K}$ were compared with those found in the database JCPDS-International Centre for Diffraction. The data permitted to assign these two reflections to $\mathrm{Cu}_{1.4} \mathrm{Mn}_{1.6} \mathrm{O}_{4}$ and $\mathrm{ZnMn}_{2} \mathrm{O}_{4}$ or/and $\mathrm{Cu}_{0.5} \mathrm{Zn}_{0.5} \mathrm{Mn}_{2} \mathrm{O}_{4}$. The binary oxide $\mathrm{Cu}_{1.4} \mathrm{Mn}_{1.6} \mathrm{O}_{4}$ (the first reflection) has a spinel structure with a cubic symmetry, the lattice constant $a=8.305 \AA$ and the space group $F d-3 m(227)$ (PDF Card number $01-071-1145)$. The second reflection at $2 \theta=36.4^{\circ}$ can be attributed to $\mathrm{ZnMn}_{2} \mathrm{O}_{4}$ (hetaerolite) or/and $\mathrm{Cu}_{0.5} \mathrm{Zn}_{0.5} \mathrm{Mn}_{2} \mathrm{O}_{4}$, both having the spinel structure. They have tetragonal symmetry with space group 


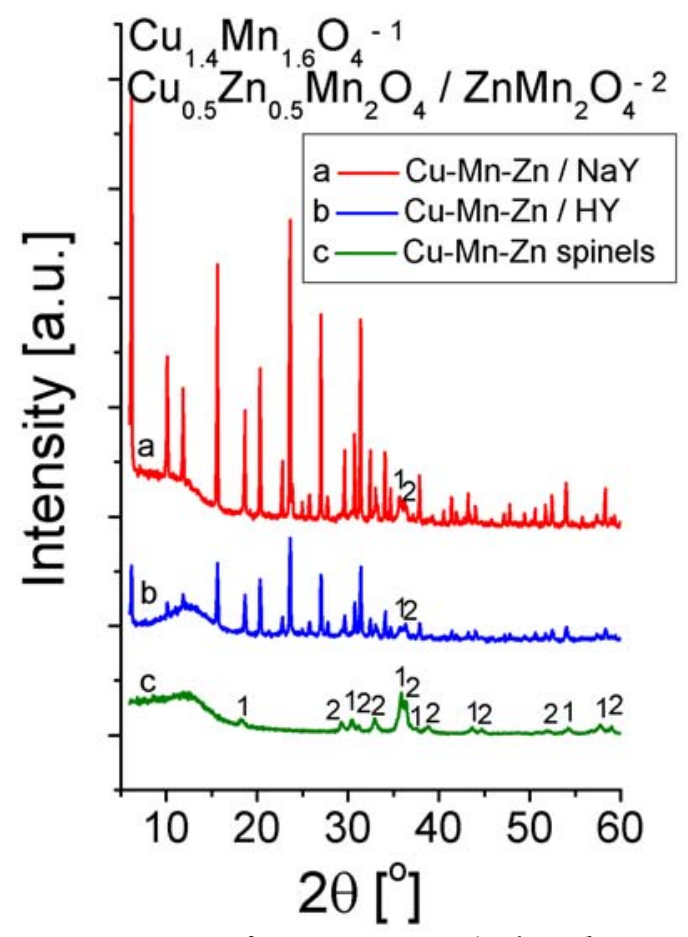

Fig. 2. XRD patterns for $\mathrm{Cu}-\mathrm{Mn}-\mathrm{Zn}$ spinels and $\mathrm{Cu}-\mathrm{Mn}-\mathrm{Zn}$ spinels loaded on $\mathrm{NaY}(10 \mathrm{wt} \%)$ and $\mathrm{HY}(10 \mathrm{wt} \%)$ zeolites.

I41/amd(141) (PDF Card number 04-005-7644 and 04-007-4373). However, in this case, a direct distinction between zinc and copper-zinc-manganite is very difficult due to very similar values of network parameters $a=5.73 \AA, c=9.25 \AA$ and $a=5.72 \AA$, $c=9.23 \AA$. The zinc and copper-zinc-manganite spinels are present in smaller amounts.

The EMR spectra of $\mathrm{Cu}-\mathrm{Mn}-\mathrm{Zn}$ spinels (10 wt\%) supported on $\mathrm{NaY}$ and $\mathrm{HY}$ zeolites were characterized by the presence of four types of EMR lines:

- A very broad EMR line, the intensity of which was strongly increased and the linewidth was reduced with the decrease in temperature. We have attributed this line to the antiferromagnetic spinels $\mathrm{Cu}_{1.4} \mathrm{Mn}_{1.6} \mathrm{O}_{4}$ and $\mathrm{ZnMn}_{2} \mathrm{O}_{4}$ or/and $\mathrm{Cu}_{0.5} \mathrm{Zn}_{0.5} \mathrm{Mn}_{2} \mathrm{O}_{4}$.

- A characteristic powder spectrum with anisotropy of the $g$ factor and the hyperfine splitting $a$ consisting of four hyperfine structure (hfs) lines, which could be attributed to a paramagnetic copper $\mathrm{Cu}^{2+}$ complex I (electron configuration $3 d^{9}$, electron spin $S=1 / 2$, ground state term $\left.{ }^{2} D_{5 / 2}\right)$. The hfs lines come from the interaction of the unpaired electron with the isotope ${ }^{63} \mathrm{Cu}$ nucleus (nuclear spin $I=3 / 2$, abundance $A=$ 0.69 ) and the isotope ${ }^{65} \mathrm{Cu}$ nucleus (nuclear spin
$I=3 / 2$, abundance $A=0.31$ ) - both isotopes having nearly equal values of nuclear magnetic moments.

- A spectrum similar to the previous one, which was assigned to another paramagnetic copper $\mathrm{Cu}^{2+}$ complex II.

- A nearly isotropic spectrum consisting of six hfs lines, attributed to a paramagnetic manganese $\mathrm{Mn}^{2+}$ complex (electron configuration $3 d^{5}$, electron high-spin $S=5 / 2$, ground state term ${ }^{6} S_{5 / 2}$ ), which is characteristic of the interaction of the unpaired electron with the isotope ${ }^{55} \mathrm{Mn}$ nucleus (nuclear spin $I=5 / 2$, abundance $A=1$ ). These lines were observed only in the case of $\mathrm{Cu}-\mathrm{Mn}$ $-\mathrm{Zn} / \mathrm{HY}$ system but not in that of $\mathrm{Cu}-\mathrm{Mn}-\mathrm{Zn}$ / $\mathrm{NaY}$ system.

The observed EMR spectra of the two $\mathrm{Cu}^{2+}$ complexes can be described by the spin Hamiltonian for axial symmetry in the form:

$$
\begin{aligned}
\hat{H}=g_{\|} \beta B_{z} \hat{S}_{z} & +g_{\perp} \beta\left(B_{x} \hat{S}_{x}+B_{y} \hat{S}_{y}\right)+A_{\|} \hat{S}_{z} \hat{I}_{z} \\
& +A_{\perp}\left(\hat{S}_{x} \hat{I}_{x}+\hat{S}_{y} \hat{I}_{y}\right)
\end{aligned}
$$

where $A_{\| \mid}=g_{||} \beta a_{\|}, A_{\perp}=g_{\perp} \beta a_{\perp}(a-$ hyperfine splitting $[\mathrm{mT}])$.

Spin Hamiltonian parameters of EMR spectra for samples containing Cu-Mn-Zn spinels supported on the $\mathrm{NaY}$ and $\mathrm{HY}$ zeolites (fresh samples) recorded at $293 \mathrm{~K}$ are given in Table 1 . The value of hfs splitting $a_{\perp}$ could not be determined, because the hfs lines at the perpendicular orientation were poorly resolved. We have found that two types of $\mathrm{Cu}^{2+}$ complexes I and II exist in the cages of the HY zeolite. Since the spin Hamiltonian parameters fulfil the inequality $g_{\|}$ $>g_{\perp}>g_{e}=2.0023$, the orbital ground state of the unpaired electron of $\mathrm{Cu}^{2+}$ cation for both complexes is $\left|x^{2}-y^{2}\right\rangle$. According to the Jahn-Teller effect, the $\mathrm{Cu}^{2+}$ complex I has the symmetry of tetragonally elongated trans-octahedron $D_{4 h}$, and $\mathrm{Cu}^{2+}$ complex II has the symmetry of tetragonally distorted tetrahedron (pseudotetrahedron) $D_{2 d}[9]$.

In the EMR spectrum of $\mathrm{Mn}^{2+}$ complex, only six hfs components originating from the $m_{s} \mid-1 / 2>$ $\rightarrow|+1 / 2\rangle$ transition were observed (see Fig. 5). Other transitions of this type were not visible due to the overlapping of fine structure lines. Between the six hfs lines, we have observed small additional peaks that resulted from the forbidden transitions described by Bleaney et al. [10]. These lines appear under circumstances where the zero-field splitting (ZFS) has to be taken into account [11].

Spinels on the surface of the zeolites maintain their original spinel structure. However, some cat-

Table 1. Spin Hamiltonian parameters of EMR spectra ( $g$ factors, hyperfine splittings $a[\mathrm{mT}]$ ) for samples containing $\mathrm{Cu}-\mathrm{Mn}-\mathrm{Zn}$ spinels supported on different zeolites (293 K)

\begin{tabular}{lccccccccc}
\hline & & \multicolumn{3}{c}{ Cu complex I } & \multicolumn{3}{c}{ Cu complex II } & \multicolumn{2}{c}{ Mn complex } \\
\cline { 2 - 10 } Carrier & $\begin{array}{c}\text { Loading } \\
{[\%]}\end{array}$ & $g_{\|}$ & $\begin{array}{c}a_{\|} \\
{[\mathrm{mT}]}\end{array}$ & $g_{\perp}$ & $g_{\|}$ & $\begin{array}{c}a_{\|} \\
{[\mathrm{mT}]}\end{array}$ & $g_{\perp}$ & $g$ & $\begin{array}{c}a \\
{[\mathrm{mT}]}\end{array}$ \\
\hline $\mathrm{NaY}$ & 10 & 2.355 & 12.3 & 2.055 & - & - & - & - & - \\
& 5 & 2.373 & 12.4 & 2.067 & 2.331 & 15.7 & 2.038 & 2.002 & 9.5 \\
$\mathrm{HY}$ & 10 & 2.373 & 12.5 & 2.065 & 2.331 & 15.6 & 2.037 & 2.001 & 9.6 \\
\hline
\end{tabular}



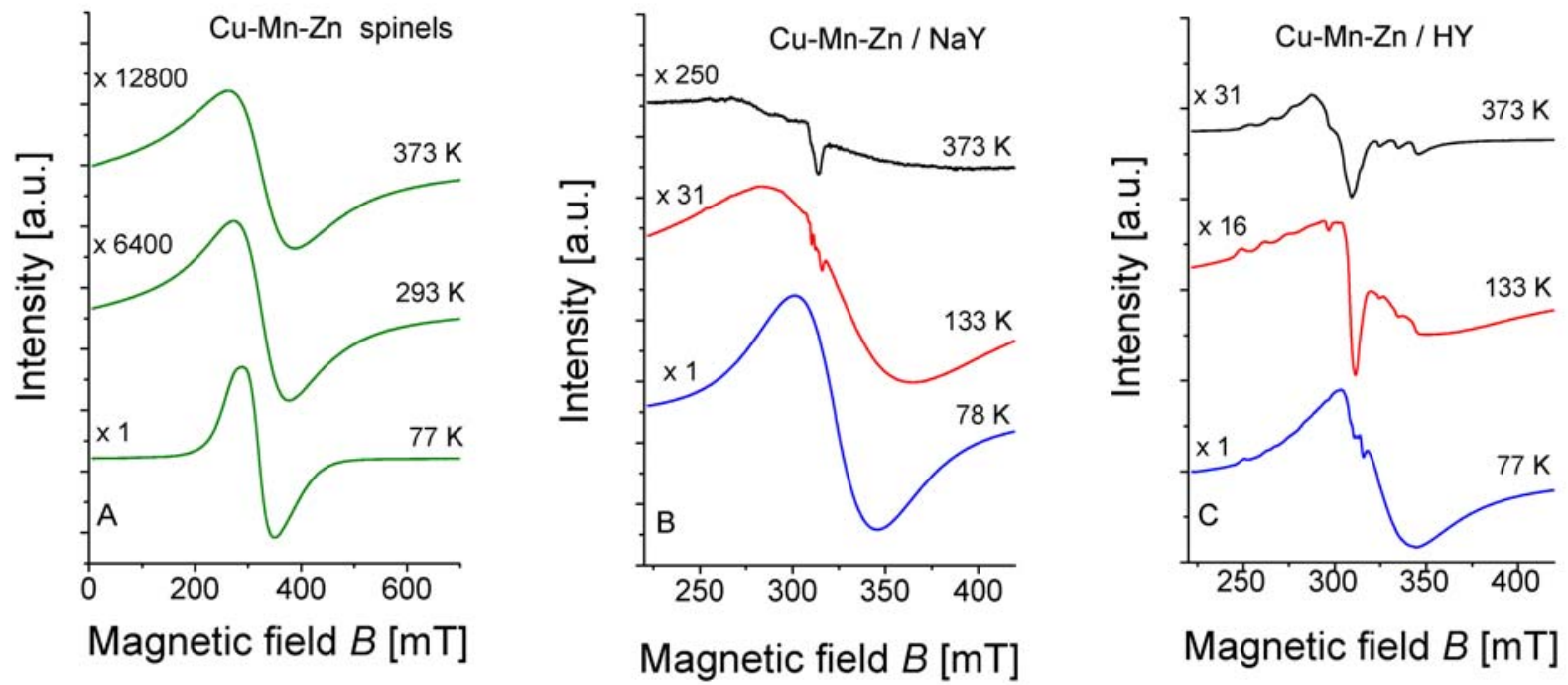

Fig. 3. Changes of EMR spectra with temperature: $\mathrm{A}-\mathrm{Cu}-\mathrm{Mn}-\mathrm{Zn}$ spinels; B - Cu-Mn-Zn/NaY (10 wt\%); C - Cu-Mn-Zn/HY (10 wt $\%)$.

ions originating from spinels bind to the surface of zeolites due to the ion-exchange $\mathrm{Cu}$ and/or $\mathrm{Mn}$ cations onto the cages of $\mathrm{Y}$ zeolite. Signals of $\mathrm{Cu}^{2+}(\mathrm{I})$, $\mathrm{Cu}^{2+}(\mathrm{II})$ and $\mathrm{Mn}^{2+}$ complexes are derived from cations located in exchangeable extra-lattice positions. No EMR lines from isolated $\mathrm{Cu}^{2+}$ and $\mathrm{Mn}^{2+}$ cations were observed in the EMR spectra of pure spinel. We have seen only a very single broad EMR line, which came from pure spinel phase (Fig. 3A). A comparison of the EMR spectrum of the bulk spinels with spinels supported on $\mathrm{NaY}$ and $\mathrm{HY}$ zeolites at $293 \mathrm{~K}$ shows that exchange interactions between electron spins in the bulk spinels were strongly reduced after loading them on zeolites. The decrease in the size of the crystallites inside the zeolite cages led to the reduction in the exchange interactions in spinels. The reduction in the exchange interactions was revealed by a significant reduction in the intensity of the EMR line.

We have studied the temperature dependence of EMR spectra for the investigated samples. Figure 3A shows the resonance spectra for antiferromagnetic
$\mathrm{Cu}-\mathrm{Mn}-\mathrm{Zn}$ spinels in the temperature range between 77 and $373 \mathrm{~K}$. It results from the aforementioned figure that the position of the resonance field $B_{\text {res }}$ remains nearly constant with temperature, but the linewidth $\Delta B_{\mathrm{pp}}$ strongly increases. It is worthy to notice that the resonance line intensity decreases with temperature.

EMR spectra of $\mathrm{Cu}-\mathrm{Mn}-\mathrm{Zn} / \mathrm{NaY}$ and $\mathrm{Cu}-\mathrm{Mn}$ $-\mathrm{Zn} / \mathrm{HY}$ recorded at $77 \mathrm{~K}$ differ significantly from those recorded at $373 \mathrm{~K}$. The EMR spectrum of $\mathrm{Cu}-\mathrm{Mn}-\mathrm{Zn} / \mathrm{NaY}$ contains only one line attributed to $\mathrm{Cu}-\mathrm{Mn}-\mathrm{Zn}$ spinels (Fig. 3B). On the contrary, in the spectrum of $\mathrm{Cu}-\mathrm{Mn}-\mathrm{Zn} / \mathrm{HY}$ sample, a smaller line from $\mathrm{Cu}^{2+}$ complex is observed, in addition to the broad line (Fig. 3C).

The intensity of the EMR lines recorded at $373 \mathrm{~K}$ for spinels supported on zeolites is very low, but it increases with decreasing temperature to $77 \mathrm{~K}$. This effect is the most clearly seen in the case of $\mathrm{NaY}$ zeolite (Fig. 3B). It is worth noting that the value of resonance induction of magnetic field $B_{\text {res }}$ is nearly constant (Fig. 4), as it was for pure spinels.

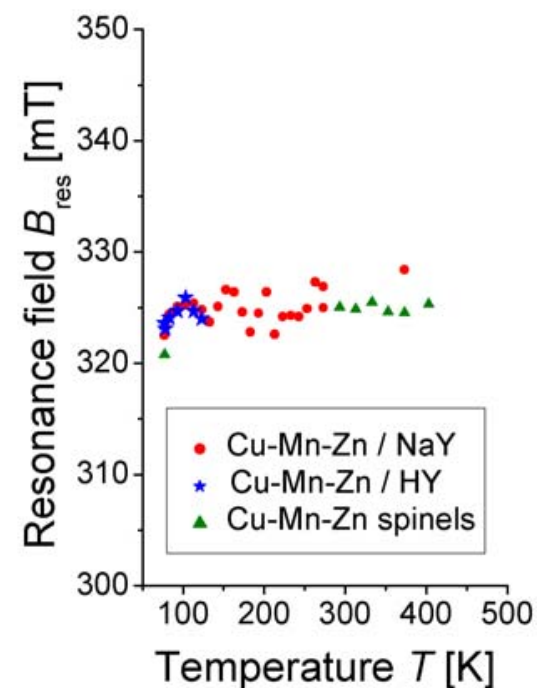

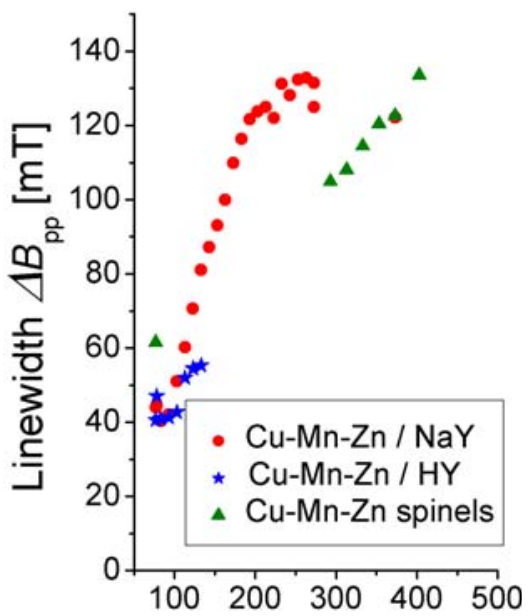

Temperature $T[\mathrm{~K}]$

Fig. 4. Temperature dependence of resonance field $B_{\text {res }}$ and linewidth $\Delta B_{\mathrm{pp}}$ for $\mathrm{Cu}-\mathrm{Mn}-\mathrm{Zn}$ spinels, $\mathrm{Cu}-\mathrm{Mn}-\mathrm{Zn} / \mathrm{NaY}$ $(10 \mathrm{wt} \%)$ and $\mathrm{Cu}-\mathrm{Mn}-\mathrm{Zn} / \mathrm{HY}(10 \mathrm{wt} \%)$. 
The decrease in temperature leads to an increase of exchange interactions between electron spins and causes a reduction in the values of the EMR linewidth $\Delta B_{\mathrm{pp}}$ (Fig. 4). The linewidth $\Delta B_{\mathrm{pp}}$ of pure spinels was well determinable to $403 \mathrm{~K}$, while the linewidth $\Delta B_{\mathrm{pp}}$ of spinels on HY zeolite was only to $133 \mathrm{~K}$. In the case of spinels supported on $\mathrm{NaY}$ zeolite, the linewidth $\Delta B_{\mathrm{pp}}$ of resonance line was determined up to $273 \mathrm{~K}$.

A comparison of the temperature dependence of EMR spectra of $\mathrm{Cu}-\mathrm{Mn}-\mathrm{Zn}$ spinels loaded onto $\mathrm{NaY}$ and HY zeolites shows that intensities of the EMR lines for the spinels in HY zeolite are weaker than those in $\mathrm{NaY}$ zeolite. It leads to the decrease of the exchange interactions between electron spins in the spinel. This points to a significant effect of the kind of aluminosilicate matrix on properties of $\mathrm{Cu}-\mathrm{Mn}-\mathrm{Zn}$ spinels. The interaction of $\mathrm{Cu}-\mathrm{Mn}-\mathrm{Zn}$ mixed oxides
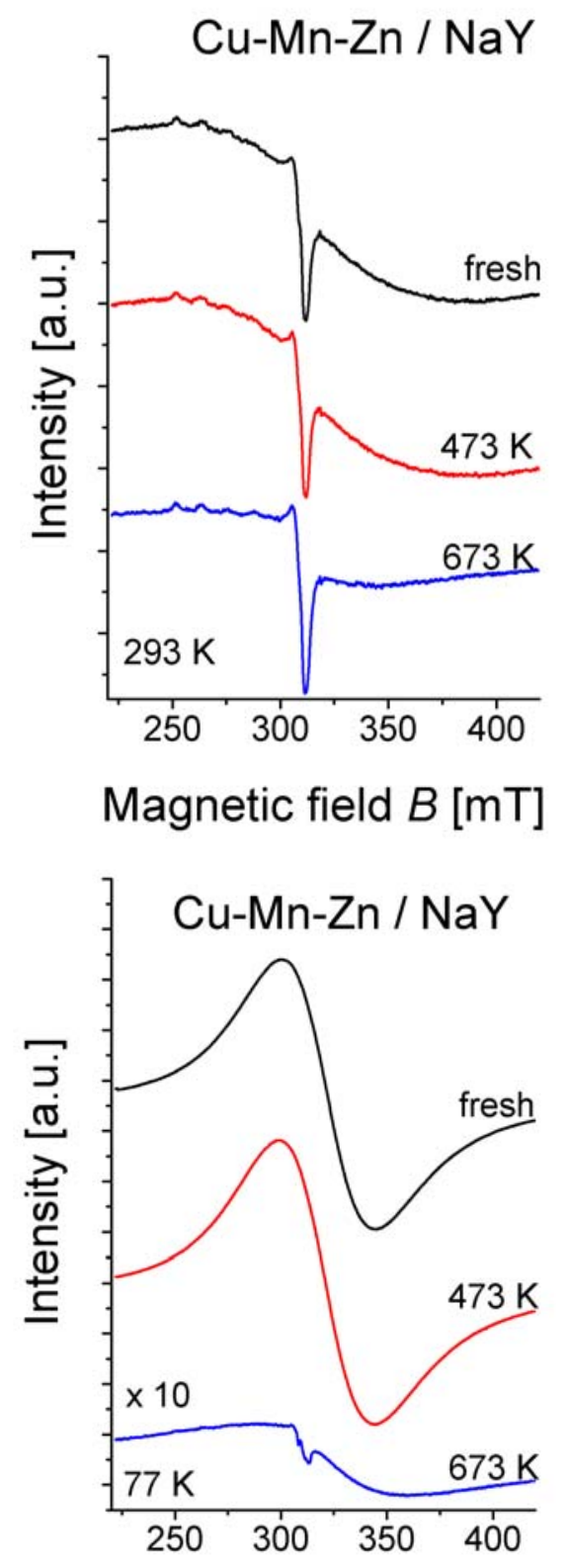

Magnetic field $B[\mathrm{mT}]$ with zeolite $\mathrm{HY}$ is stronger than that with zeolite $\mathrm{NaY}$ (Fig. 3B and Fig. 3C).

The spin Hamiltonian parameters of $\mathrm{Cu}^{2+}$ and $\mathrm{Mn}^{2+}$ complexes did not change with temperature for both zeolites.

The samples $\mathrm{Cu}-\mathrm{Mn}-\mathrm{Zn} / \mathrm{NaY}$ and $\mathrm{Cu}-\mathrm{Mn}-\mathrm{Zn} /$ HY were evacuated at different temperatures. The EMR spectra of evacuated samples recorded at room temperature did not show significant changes of the lineshape, the line intensity and the spin Hamiltonian parameters. In the case of samples heated and evacuated at $673 \mathrm{~K}$, the intensity of EMR spectra was reduced, if recorded at $77 \mathrm{~K}$ (Fig. 5). This indicates that after the evacuation at $673 \mathrm{~K}, \mathrm{Cu}-\mathrm{Mn}-\mathrm{Zn}$ spinels deposited on $\mathrm{NaY}$ and $\mathrm{HY}$ zeolites lost their stability. It is worth noting that for the sample $\mathrm{Cu}-\mathrm{Mn}-\mathrm{Zn}$ / $\mathrm{NaY}$, the line intensity was reduced by one order of magnitude. This may suggest that $\mathrm{Cu}-\mathrm{Mn}-\mathrm{Zn}$ antifer-
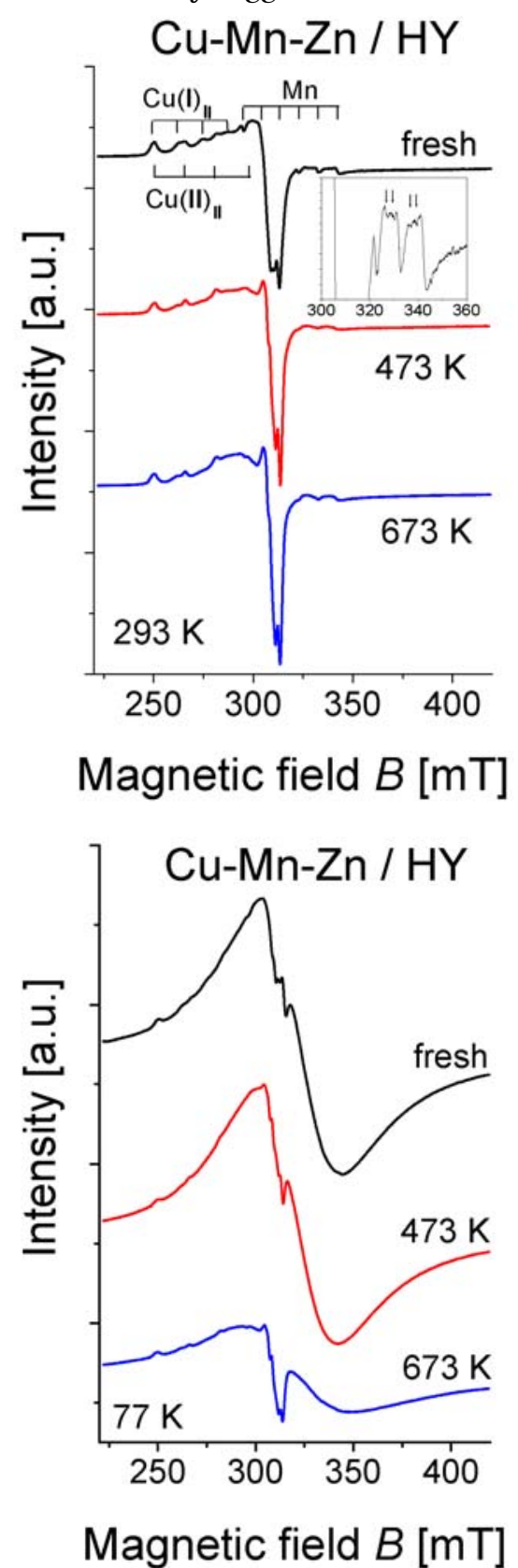

Fig. 5. EMR spectra of $\mathrm{Cu}-\mathrm{Mn}-\mathrm{Zn} / \mathrm{NaY}(10 \mathrm{wt} \%)$ and $\mathrm{Cu}-\mathrm{Mn}-\mathrm{Zn} / \mathrm{HY}(10 \mathrm{wt} \%)$ samples evacuated at different temperatures for $2 \mathrm{~h}$ recorded at $293 \mathrm{~K}$ and $77 \mathrm{~K}$. The arrows in the inset show the forbidden transitions for ${ }^{55} \mathrm{Mn}$. 
romagnetic spinels on $\mathrm{HY}$ zeolite are more stable than those on $\mathrm{NaY}$ zeolite.

We believe that this phenomenon is caused by differences in the acid properties of the $\mathrm{NaY}$ and HY zeolites. FTIR measurements of samples with adsorbed pyridine have shown that the strength of acid centers on HY zeolite was much greater than that on $\mathrm{NaY}$ zeolite.

\section{Conclusions}

The study on the influence of Y type zeolites on EMR spectra of supported copper-manganese-zinc mixed oxide spinels have brought us the following conclusions.

The analysis of EMR spectra proved the occurrence of interactions between $\mathrm{Cu}-\mathrm{Mn}-\mathrm{Zn}$ spinels and $\mathrm{NaY}$ and $\mathrm{HY}$ zeolites. The results of EMR measurements point to the appearance of paramagnetic complexes containing $\mathrm{Cu}^{2+}$ and $\mathrm{Mn}^{2+}$ cations.

The type of zeolite ( $\mathrm{NaY}$ or $\mathrm{HY}$ ) determines the character of the EMR spectrum of the investigated samples. In EMR spectra of $\mathrm{Cu}-\mathrm{Mn}-\mathrm{Zn} / \mathrm{NaY}$ and $\mathrm{Cu}-$ -Mn-Zn/HY samples recorded at $293 \mathrm{~K}$ the presence of two $\mathrm{Cu}^{2+}$ complexes was observed (octahedral coordinated $\mathrm{Cu}^{2+}$, as well as $\mathrm{Cu}^{2+}$ in pseudotetrahedral environment), whereas in the case of $\mathrm{Cu}-\mathrm{Mn}-\mathrm{Zn} /$ $\mathrm{HY}$ sample an additional signal coming from $\mathrm{Mn}^{2+}$ complex was recorded.

During the evacuation of all samples at $673 \mathrm{~K}$, the signal intensity in the EMR spectra measured at $77 \mathrm{~K}$ was reduced. For $\mathrm{Cu}-\mathrm{Mn}-\mathrm{Zn} / \mathrm{NaY}$, this reduction was significantly greater than that for $\mathrm{Cu}-\mathrm{Mn}$ $-\mathrm{Zn} / \mathrm{HY}$. It was proved that different strength of interactions between the zeolites and the $\mathrm{Cu}-\mathrm{Mn}-\mathrm{Zn}$ spinels results from differences in the acidity of $\mathrm{NaY}$ and HY zeolites.

Acknowledgment. The authors are grateful to Professor Maria Ziółek and Professor Ryszard Fiedorow for fruitful discussions.

\section{References}

1. Fierro, G., Morpurgo, S., Lo Jacono, M., Inversi, M., \& Pettiti, I. (1998). Preparation, characterisation and catalytic activity of $\mathrm{Cu}-\mathrm{Zn}$-based manganites obtained from carbonate precursors. Appl. Catal. A-Gen., 166(2), 407-417. DOI: 10.1016/S0926860X(97)00283-4.

2. Fei, J. H., Yang, M. X., Hou, Z. Y., \& Zheng, X. M. (2004). Effect of the addition of manganese and zinc on the properties of copper-based catalyst for the synthesis of syngas to dimethyl ether. Energy Fuels, 18(5), 1584-1587. DOI: 10.1021/ef049961f.

3. Fei, J. H., Hou, Z. Y., Zhu, B., Lou, H., \& Zheng, X. M. (2006). Synthesis of dimethyl ether (DME) on modified HY zeolite and modified HY zeolite-supported Cu-Mn-Zn catalysts. Appl. Catal. A-Gen., 304, 49-54. DOI: 10.1016/j.apcata.2006.02.019.

4. Padlyak, B. V., Wojtowicz, W., Adamiv, V. T., Burak, Ya. V., \& Teslyuk, I. M. (2010). EPR spectroscopy of the $\mathrm{Mn}^{2+}$ and $\mathrm{Cu}^{2+}$ centres on lithium and potassium-lithium tetraborate glasses. Acta Phys. Pol. A, 117(1), 122-125.

5. Guskos, N., Glenis, S., Typek, J., Żołnierkiewicz, G., Berczyński, P., Wardal, K., Guskos, A., Sibera, D., Moszyński, D., Łojkowski, W., \& Narkiewicz, U. (2012). Magnetic properties of $\mathrm{ZnFe}_{2} \mathrm{O}_{4}$ nanoparticles. Cent. Eur. J. Phys. 10(2), 470-477. DOI: 10.2478/s11534012-0013-3.

6. Zapotoczny, B., Dudek, M. R., Guskos, N., Kozioł, J. J., Padlyak, B. V., Kośmider, M., \& Rysiakiewicz-Pasek, E. (2012). FMR study of the porous silicate glasses with $\mathrm{Fe}_{3} \mathrm{O}_{4}$ magnetic nanoparticles fillers. $J$. Nanomater., 2012, article ID 341073(7pp.). DOI: $10.1155 / 2012 / 341073$.

7. Jiang, M., \& Karge, H. G. (1995). FTIR study of the kinetics of solid-state ion exchange in zeolites using pyridine as a probe. J. Chem. Soc. Faraday Trans., 91(12), 1845-1851. DOI: 10.1039/ft9959101845.

8. Karge, H. G., Hunger, M., \& Beyer, H. K. (1999). Characterization of zeolites - infrared and nuclear magnetic resonance spectroscopy and X-ray diffraction. In J. Weitkamp \& L. Puppe (Eds.), Catalysis and zeolites: Fundamentals and applications (pp. 198-326). Berlin: Springer-Verlag.

9. Goslar, J., \& Więckowski, A. B. (1985). Migration and structure of aqueous $\mathrm{Cu}^{2+}$ complexes in Faujasite. J. Solid State Chem., 56(1), 101-115. DOI: 10.1016/0022-4596(85)90257-9.

10. Bleaney, B., \& Rubins, R. S. (1961). Explanation of some 'forbidden' transitions in paramagnetic resonance. Proc. Phys. Soc., 77(1), 103-112. DOI: 10.1088/0370-1328/77/1/312.

11. Lender, Z., Goldfarb, D., \& Batista, J. (1993). Magnetic resonance studies of SAPO-44 and MnAPSO-44. J. Am. Chem. Soc., 115(3), 1106-1114. DOI: 10.1021/ja00056a040. 